\title{
Ansiedade pré-competitiva em atletas das categorias de base: relato de experiência em campeonato brasileiro de judô
}

\author{
Pre-competitive anxiety in athletes of the judo base categories: \\ experience report of brazilian judo championship
}

DOI: http://dx.doi.org/10.36453/2318-5104.2019.v17.n2.p77

\author{
Jaqueline Puquevis de Souza ${ }^{1}$, Cristina Costa Lobo르, Carlos Leonardo dos Anjos ${ }^{1}$, \\ Luiz Felipe Mikulis Passareli ${ }^{1}$ \\ ${ }^{1}$ Faculdade Guairacá \\ ${ }^{2}$ Instituto de Estudos Superiores de Fafe
}

\section{RESUMO}

Introdução: A ansiedade pré-competitiva constitui-se um dos temas mais estudados dentre os fatores psicológicos, para o desempenho em competições de alto rendimento. Quando se trata de categorias de base esta pressão pode ser maior, considerando a estrutura psíquica e a idade destes pequenos atletas. Objetivo: O objetivo deste relato é discutir teoricamente sobre os conceitos de estresse e ansiedade pré-competitiva, descrevendo uma experiência de aquisição de técnicas e comportamentos dos participantes por meio de um treinamento de habilidades mentais no dia da competição. Métodos: Este estudo foi realizado a partir das observações de quatro atletas entre 11 e 13 anos no Campeonato Brasileiro de Judô em 2018, após um período de sete meses de treinamentos de habilidades mentais, realizadas em um projeto de intervenção em Psicologia do Esporte. Resultados: Por meio de relatos e observações forma observados o uso de estratégias e técnicas para redução de ansiedade, utilizadas pelos quatro atletas participantes do projeto. Conclusão: Os resultados demonstraram que os fatores situacionais como sensações corporais somáticas e pensamentos disfuncionais, denotaram os principais modos como à ansiedade foi vivenciada por estas crianças. As técnicas aprendidas no treinamento mental vivenciado pelos atletas, foram aplicadas na competição e tiveram impacto positivo no controle das ansiedades cognitiva e somática.

PALAVRAS-CHAVE: Ansiedade; Judô; Treinamento Mental.

\section{ABSTRACT}

Brackground: Pre-competitive anxiety is one of the most studied themes among psychological factors for performance in high performance competitions. When it comes to grassroots categories this pressure can be higher considering the psychic structure and age of these little athletes. Objective: The objective of this report is to discuss theoretically the concepts of pre-competitive stress and anxiety, describing an experience of acquiring participants' techniques and behaviors through a training of mental skills on the day of competition. Methods: This study was conducted from the observations of four athletes between 11 and 13 years old at the Brazilian Judo Championship in 2018, after a seven-month period of mental skills training, performed in an intervention project in Sports Psychology. Results: Through reports and observations, it was observed the use of strategies and techniques for anxiety reduction, used by the four athletes participating in the project. Conclusion: The results showed that situational factors such as somatic body sensations and dysfunctional thoughts, denoted the main ways anxiety was experienced by these children. The techniques learned in the mental training experienced by the athletes were applied in competition and had a positive impact on the control of cognitive and somatic anxieties.

KEYWORDS: Keywords: Anxiety; Judo; Mental Training. 


\section{INTRODUÇÃO}

A Psicologia do Esporte delineada como uma ciência que busca compreender o indivíduo e seus comportamentos na prática esportiva ou da atividade física, tem buscado atuar com as possibilidades de aperfeiçoamento e maximização de potencial nos esportes de rendimento, além dos benefícios para saúde física e mental de seus praticantes. $O$ treinamento de habilidades mentais é uma das possibilidades de atuação em práticas de intervenção (PINHO, 2016).

Estudos sobre as reações emocionais que envolvem o comportamento de atletas infanto-juvenil antes das competições, constituem uma importante referência para auxiliar os esportistas a entenderem e a controlarem o estresse e a ansiedade em situações pré-competitivas. Assim, tanto o estresse quanto a ansiedade são considerados aspectos determinantes para o desempenho esportivo e, quando regulados, tornam-se aliados da ativação ideal de atletas de alto rendimento (WEINBERG; GOULD, 2017).

No meio esportivo a ansiedade negativa pode vir a atrapalhar o atleta. De acordo com Barlow e Durand (2008), caracteriza-se por um conjunto de sintomas comportamentais e fisiológicos, que se referem a uma preocupação com relação ao futuro e ao humor negativo. Dentre alguns sintomas e comportamentos podem ser destacados: inquietação, taquicardia, tensão muscular, tremor, mal estar estomacal, sudorese, pensamentos negativos, dores de cabeça, falta de concentração entre outros. Para Fabiani (2008) a ansiedade quando controlada pode ter caráter positivo favorecendo a ativação ideal do atleta nas competições. O bom desempenho requer um nível de ansiedade que o permita manter um bom nível de ativação, para que não entre de forma demasiadamente relaxada e com baixa motivação. Quando isto acontece e a ansiedade está equilibrada e o atleta pode manter o controle de suas emoções.

Diante destes fatores esta pesquisa tem como problemática a seguinte questão: a atuação da psicologia do esporte por meio de suas intervenções e técnicas de controle da ansiedade pode auxiliar na regulação dos efeitos negativos da ansiedade sobre o desempenho de atletas infanto-juvenis? Diante das intervenções realizadas e levantamentos das necessidades observadas, esta pesquisa busca discutir os resultados de um treinamento de habilidades mentais em psicologia do esporte delineado a seguir.

\section{MÉTODOS}

Esta análise parte da observação dos comportamentos em um campeonato brasileiro de judô, buscando identificar se as técnicas ensinadas em um Treinamento de Habilidades Psicológicas (THP) foram utilizadas. O THP busca melhorar o desempenho esportivo, por meio de uma abordagem educacional e ensino de técnicas aos atletas, trabalhando as habilidades cognitivas como atenção, concentração, motivação, tomada de decisão e ansiedade (WEINBERG; GOULD, 2017).

O THP foi realizado por um projeto de extensão em Psicologia do Esporte denominado Centro de Investigação e Intervenção, Desporto, Educação e Bem Estar (CIIDEBE) da Faculdade Guairacá na cidade de Guarapuava. As intervenções foram realizadas com atletas da categoria de base de judô, com idades entre 11 e 13 anos. Após as intervenções realizadas durante sete meses pelos estagiários do projeto e orientadora, os atletas foram acompanhados e observados pela professora responsável, na Final do Campeonato Brasileiro de Judô, Região 5, ocorrido entre os dias 13 e 14 de abril de 2018, na cidade de Itapecerica da Serra (SP).

Por isto, este estudo caracteriza-se como uma pesquisa de campo buscando informações e dados diretamente com o público pesquisado, exigindo do pesquisador uma relação mais direta com o objeto pesquisado. É preciso ir ao espaço onde o fenômeno ocorre e reunir um conjunto de informações a serem analisadas e documentadas (GONÇALVES, 2001). Para a coleta de dados foi utilizado como instrumento a Pesquisa de Observação que consiste em analisar o que as pessoas fazem, através do processo sistemático de registro de padrões do comportamento dos atletas (DUARTE, 2017).

As técnicas ensinadas tinham como objetivo auxiliar os atletas a lidarem com suas emoções e manterem sua autorregulação (SAMULSKI, 2002). Foram utilizadas técnicas cognitivas para redução dos fatores estressores como: técnicas de processamento cognitivo; técnica de auto-fala; que em resumo são um tipo de instrução que o atleta fornece a ele mesmo, por meio da repetição de palavras pré-definidas com o psicólogo do esporte (SCALA, KERBAUY, 2005). No segundo momento foram trabalhadas as técnicas somáticas como a respiração, buscando auxiliar na minimização dos sintomas corporais como: sudorese, tremor, batimentos cardíacos acelerados, dentre outros, que podem interferir no desempenho do atleta (SAMULSKI, 2002). Elas também auxiliam no autocontrole sobre corpo e mente e na regulação psicofisiológica (WILLHELM et al., 2015).

O relaxamento é outra ferramenta utilizada para controlar a ativação do sistema nervoso central, eliciada por diferentes estímulos ambientais. Por meio dele o atleta aprende a discriminar as modificações que ocorrem no seu corpo e a encontrar qual a ativação adequada, para cada situação e para um bom desempenho (SCALA, 2000). 
Por último, o THP focou na técnica da visualização ou mentalização, que consiste em recuperar da memória fragmentos de informações armazenados de experiências do passado e transformá-los em imagens com algum significado (WEINBERG; GOULD, 2017). Foram analisados os comportamentos no dia da competição para observar se os instrumentos e técnicas aprendidos seriam utilizados pelos atletas.

\section{RESULTADOS}

Os resultados abaixo descrevem as reações emocionais e comportamentais de cada atleta, bem como as técnicas utilizadas por eles no momento pré-competitivo. Os atletas serão representados por codinomes (Quadro 1).

Quadro 1. Observação sistemática de comportamentos dos atletas na competição.

\begin{tabular}{|c|c|c|c|c|}
\hline Atleta & Idade & Ansiedade Cognitiva & Ansiedade somática & Técnica utilizada pelo atleta \\
\hline Paulo & 11 & $\begin{array}{l}\text { Desvio da capacidade do } \\
\text { estado de consciência (rela- } \\
\text { tava não enxergar a quadra) } \\
\text { e ter medo. }\end{array}$ & $\begin{array}{l}\text { Frequência cardíaca alterada, di- } \\
\text { latação da pupila, modificação na } \\
\text { cor da pele, extremidades do corpo } \\
\text { geladas. }\end{array}$ & $\begin{array}{l}\text { Respiração e relaxamento buscando e trazendo o atleta } \\
\text { para o momento presente, redirecionando o seu olhar } \\
\text { para a quadra. Técnica da visualização e mentalização. } \\
\text { respiração diafragmática e acupressão. }\end{array}$ \\
\hline João & 12 & Não foi observado sintomas. & $\begin{array}{l}\text { Alteração da frequência cardíaca, } \\
\text { náuseas e falta de ar. }\end{array}$ & $\begin{array}{l}\text { Relaxamento muscular progressivo, acupressão e auto- } \\
\text {-fala. }\end{array}$ \\
\hline Carina & 12 & $\begin{array}{l}\text { Comportamentos de raiva } \\
\text { extrema nas competições, } \\
\text { sem motivo específico. }\end{array}$ & Não foi observado sintomas. & Técnica de respiração para regular os níveis de ativação. \\
\hline Ivan & 13 & Não foi observado sintomas. & $\begin{array}{l}\text { Frequência cardíaca alterada, mãos } \\
\text { trêmulas dificultando a firmeza para } \\
\text { segurar o kimono do adversário. }\end{array}$ & Técnicas de respiração e relaxamento. \\
\hline
\end{tabular}

No momentos que antecederam a competição o atleta fez uso das técnicas aprendidas no THM, podendo ser observado a redução dos de ansiedade possibilitando uma melhora nos níveis de ativação do atleta. $O$ atleta obteve bons resultados e ficou com $3^{\circ}$ lugar (bronze). Com o trabalho realizado, os níveis de ansiedade cognitiva foram reduzidos e o atleta obteve bom desempenho em suas lutas.

$\mathrm{O}$ atleta Jõao mostrou-se focado, sem dispensar energia com pulos e saltos excessivos, como costumava fazer em quadra antes de outras provas. Este atleta obteve o ouro em sua categoria. $\mathrm{O}$ atleta possui a crença que quanto mais raiva adquire, maior e melhor é seu desempenho. A atleta Carina utilizou apenas a técnica de respiração para regular os níveis de ativação. Obteve bons resultados conquistando a medalha de prata em sua categoria. Já o atleta Ivan utilizou mostrouse eficaz as técnicas de respiração e relaxamento, obtendo bons resultados, mas não trouxe medalha.

As técnicas para redução dos níveis de ansiedade já estavam sendo trabalhadas, há sete meses antes da competição, no formato semanal com duração de uma hora. Diante de um trabalho continuo e permanente, as técnicas se mostraram efetivas no dia da competição, já que os atletas vinham aplicando as técnicas nos treinamentos e em outras competições, de menor importância.

Constitui-se um fator relevante na observação em psicologia do esporte aos fatores externos geradores de ansiedade percebidos que podem interferir no desempenho, afim, de levantar dados para auxiliar a equipe técnica na prevenção das variáveis controláveis, e no controle e redução da ansiedade. No dia do campeonato brasileiro alguns destes fatores percebidos, foram:

- Metragem correta do kimono (quando não atingem as medidas corretas, causa grande insegurança na criança, desfocando a atenção e gerando comportamento de ansiedade somática).

- A chegada com antecedência no local da prova também é um fator fundamental, esta deve ser feita com grande espaço de tempo, pois auxilia o atleta no controle da área, na adaptação ao local, segurança frente à competição. A possibilidade de atraso ou tempo curto causa ansiedade, alteração de frequência cardíaca, sensação de medo, insegurança, relatos pelos mesmos. 


\section{CONSIDERAÇÕES FINAIS}

O objetivo geral deste estudo foi compreender o estresse e a ansiedade pré-competitiva, analisando as possibilidades de intervenção e atuação da psicologia do esporte. Pode-se concluir que a ansiedade competitiva pode ser saudável para ativar o atleta, mas quando experimentada de forma muito intensa, tende a minimizar seu potencial de desempenho e que a psicologia pode contribuir, se trabalhada de forma continua. Diante das intervenções realizadas pelo treinamento de habilidades mentais para atletas das categorias de base do judô, por um projeto de extensão em Psicologia do Esporte, pode-se observar na final de um campeonato brasileiro os resultados obtidos, pelas práticas vivenciadas pelos atletas.

É importante ressaltar que os resultados obtidos no dia da competição, foram possíveis pelo treinamento realizado durante sete meses que antecederam o campeonato. $\mathrm{O}$ atleta precisa ter treinamento e acompanhamento contínuo e não apenas no momento competitivo. Todas as técnicas foram ensinadas e treinadas com os participantes, de forma que pudessem aprender e aplicá-las em sua atuação quando sentissem necessidade, em momentos de pré-competição ou durante os campeonatos, mesmo sem a presença do psicólogo. As técnicas aplicadas no dia da competição obtiveram resultados positivos, pois os quatro atletas acompanhados, conseguiram diminuir os sintomas apresentados e obtiveram bons resultados.

Conclui-se que os fatores psicológicos que influenciam o atleta infantil no momento pré-competitivo, podem ser determinantes para o desempenho esportivo. Cada atleta reage de maneira subjetiva, frente ao ambiente de prova, cabendo ao profissional da psicologia auxiliar o atleta durante os treinamentos e nos momentos competitivos. Com análise dos resultados pode-se pensar que a psicologia do esporte em um trabalho continuo, tem muito a acrescentar, no treinamento das habilidades psicológicas e na maximização de resultados, com auxílio do controle de ansiedade e estresse dos atletas.

\section{REFERÊNCIAS}

BARLOW, D. H.; DURAND, V. M. Psicopatologia: uma abordagem integrada. São Paulo: CENAGE Learning, 2008. BECKER JUNIOR, B. Manual de psicologia do esporte e exercício. Novo Hamburgo: Feevale, 1999.

CHENG, W. K.; HARDY, L.; MARKLAND, D. Toward a three-dimensional conceptualization of performance anxiety: Rationale and initial measure- ment development. Psychologyof Sport and Exercise, Amsterdam, v. 10, n. 2, p. $271-8,2009$.

CORNELIAN, B. R.; MOREIRA, J.; OLIVEIRTAA, L. P. O.; RAFAEL, M. C. Acupressão aplicada nas aulas de educação física do ensino fundamental II: estudo sobre os níveis de atenção em escolares. In: VIII EPCC - Encontro Internacional de Produção Científica Cesumar. Anais... Cesumar, Maringá, 2013

DE ROSE JUNIOR, D. História e evolução da psicologia do esporte. Revista Paulista de Educação Física, São Paulo, v. 6, n. 2, p. 73-8, 1992.

DUARTE, V. M. N. Técnica de observação. Monografias Brasil escola. Disponível em: <https://monografias. brasilescola.uol.com.br/regras-abnt/tecnica-observacao.htm>. Acesso em: 23 de setembro de 2018.

FABIANI, M. T. Psicologia do esporte: a ansiedade e o estresse pré-competitivo. Curitiba: PUCPR, 2008. Disponível em: <http://www.pucpr.edu.br/eventos/educere/educere2008/anais/pdf/182 454.pdf>. Acessado em: 17 de abril de 2018.

GARCIA, E. Pesquisa bibliográfica versus revisão bibliográfica - uma discussão necessária. Revista Língua e Letras, Cascavel, v. 17, n. 35, p. 291-4, 2015.

GONÇALVES, E.P. Iniciação à pesquisa científica. Campinas: Editora Alínea, 2001.

MARGIS, R.; PICON, P.; COSNER, A. F.; SILVEIRA, R. de O. Relação entre estressores, estresse e ansiedade. Revista de Psiquiatria do Rio Grande do Sul, Porto Alegre, v. 25, n. 1, p. 65-74, 2003.

McGRATH, M.; KAWACHI, I.; ASCHERIO, A.; COLDITZ, G. A.; HUNTER, D. J.; DE VIVO, I. Association between catechol-O-methyltransferase and phobic anxiety. American Journal of Psychiatry, Washington, n. 161, p. 17035, 2004.

PINHO, H. S. A psicologia e o psicólogo do esporte: uma formação necessária. 2016. 80f. Dissertação (Mestrado em Desenvolvimento Humano e Saúde) - Universidade de Brasília, Brasília, 2016.

RUBIO, K. Da psicologia do esporte que temos à psicologia do esporte que queremos. Revista Brasileira de Psicologia do Esporte, São Paulo, v. 1, n. 1, p. 1-13, 2007.

RUBIO, K. Uma psicologia do esporte: histórico e áreas de atuação e pesquisa. Psicologia: Ciência e Profissão, Brasília, v. 19, n. 3, p. 60-9, 1999. 
SAMULSKI, D. Psicologia do esporte. Barueri: Manole, 2002.

SCALA, C. T.; KERBAUY, R. R. Autofala e esporte: estímulo discriminativo do ambiente natural na melhora de rendimento. Revista Brasileira de Comportamento Cognitivo, São Paulo, v. 7, n. 2, p. 145-58, 2005

SCALA, C. T. Proposta de intervenção em psicologia do esporte. Revista Brasileira de Comportamento Cognitivo, São Paulo, v. 2, n. 1, p. 53-9, 2000.

VIEIRA, L. F. Psicologia do esporte: uma área emergente da psicologia. Psicologia em Estudo, Maringá, v. 15, n. 2, p. 391-9, 2010

WEINBERG, R. S.; GOULD, D. Fundamentos da psicologia do esporte e do exercício. 6. ed. Porto Alegre: Artmed, 2017.

WILLHELM, A. R.; ANDRETTA, I.; UNGARETTI, M. S. Importância das técnicas de relaxamento na terapia cognitiva para ansiedade. Contextos Clínicos, São Leopoldo, v. 8, n. 1, p. 79-86, 2015.

Autor correspondente: Jaqueline Jaqueline Puquevis de Souza

E-mail: jaquepuquevis@yahoo.com.br

Recebido: 19 de agosto de 2019.

Aceito: 13 de setembro de 2019. 